\title{
SPECIFICS OF TEACHING THE INVERSE RELATIONS BETWEEN THE ARITHMETIC OPERATIONS ADDITION AND SUBTRACTION DURING THE EDUCATION IN MATHEMATICS IN GRADE 1 \\ Maria Temnikova ${ }^{1}$
}

\begin{abstract}
One of the fundamental knowledge in mathematics in Primary school is related to the arithmetic operations addition and subtraction. According to the educational programs in mathematics in the Republic of Bulgaria, students start studying these operations in grade 1 .

The article presents theoretical concepts affecting studying the arithmetic operations addition and subtraction in the education in mathematics at a primary school.

The research work identified the specifics of studying the inverse connections between the arithmetic operations addition and subtraction in the education in mathematics for grade 1 are also presented. Some of the significant tasks with importance for discovering the relations between the forward operation addition and the reverse operation subtraction were proposed in the study. A new methodology system of work with tasks where these relations are used was developed and tested.

The author studied the knowledge, skills, and competencies of the grade 1 students to solve arithmetic operations addition and subtraction tasks. After the exit diagnostic, it was found out that the students of the class where the new methodology system of work was applied during their education in mathematics have got a higher level of knowledge and skills from competency Cluster Numbers in respect of the arithmetic operations addition and subtraction.
\end{abstract}

The use of mathematical tasks with reverse relations between the arithmetic operations addition and subtraction help the students to develop both the overall mathematical knowledge and the logical thinking of the first-graders.

UDC Classification: 37.01, DOI: https://doi.org/10.12955/pss.v2.242

Keywords: inverse connections, arithmetic operations addition and subtraction

\section{Introduction}

During their Primary school education in mathematics in the Republic of Bulgaria, students acquire knowledge from arithmetic, geometry, and algebra and lead is the knowledge in arithmetic.

The expected results from the education in mathematics for grade 1 are specified in the respective educational program approved by the Ministry of Education. According to this program, students are expected to acquire knowledge and skills to perform the arithmetic operations addition and subtraction of natural numbers up to 20 and to use the relationship between addition and subtraction to find the value of numerical expressions.

Here important is the presence of pairs of inverse arithmetic operations in the educational content in mathematics for grades 1-4 and one such pair is the arithmetic operations addition and subtraction.

The foundations of the reverse relations between addition and subtraction are laid in grade 1 . Their use facilitates the students to develop knowledge, skills, and competencies for the arithmetic operations addition and subtraction, thus overcoming the most frequent mistakes which they do in subtraction of numbers up to 20 with passing the ten. This interrelation is getting updated and applied during the education in mathematics in the next years of education.

This research aims to develop a methodology system with mathematical tasks incorporating the inverse relationship between the operations addition and subtraction. The application of this new system of work will facilitate the students to develop knowledge, skills, and competencies for the arithmetic operations addition and subtraction with numbers up to 20 .

The object of the research work is the process of education in grade 1 .

The subject of the study is the efficiency of the new methodology system of work on the level of arithmetic knowledge, skills, and competencies of the students related to the operations addition and subtraction of numbers up to 20 .

The following methods are used in the research work: content analysis, didactical experiment, observation, tests, mathematics-statistics methods for processing the results.

\footnotetext{
${ }^{1}$ Trakia University, Faculty of Education, Stara Zagora, Bulgaria, mpt66@abv.bg
} 


\section{Literature review}

After analyzing Bulgarian and foreign publications, it was found out that there is a number of research works regarding the process of teaching the arithmetic operations addition and subtraction in Primary school as well as the relevant methodology of work.

According to Munasinghe (2013), one of the main concepts studied by children is the arithmetic operation addition. Mukunthan (2021) made a review of the mistakes done by the students in Primary school related to the operation addition. Additionally, Primary school students' strategies for mental addition and subtraction computations have been studied by Mastrothanasis et al. (2018). Torbeyns et al. (2018) studied the use of the subtraction by addition strategy as an important mental calculation strategy for children with different levels of achievement in mathematics.

Kllogjeri et al. (2015) presented a dynamic model developed by Geo Gebra regarding addition and subtraction. Thirunavukkarasu and Senthilnathan (2014), in their research work, studied the effectiveness of the Bar Model in enhancing the learning of mathematics at the primary level. In their article Parwines and Noornia (2019) presented their vision about the requirement to remove borrowing techniques in clearly subtraction operations in elementary school. Stigler et al. (1986) analyzed different addition and subtraction text tasks in American and Soviet elementary textbooks in mathematics.

In one of his research works, Campbell studied the problem of subtraction by addition during the process of students' education. He wrote (Campebell, 2008, p. 1094), that 'University students' self-reports indicate that they often solve basic subtraction tasks $(13-6=7)$ by reference to the corresponding addition tasks $(6+7=13$; therefore, $13-6=7)$. In this case, solution latency should be faster with subtraction tasks presented in addition format $(6+=13)$ than in standard subtraction format $\left(13-6={ }_{-}\right)$. Another research work done by Nunes et al. (2009) refers to the way of introducing to the children the problem with the inverse relation between addition and subtraction.

Angelova wrote (Angelova, 2013, p.18) that Erdniev et al. (1986) "presented his research work regarding the simultaneous studying of interconnected topics and found out that in this way preconditions for conscious learning of the connections and relations between the arithmetic operations are getting created during the education in mathematics."

Erdniev et al. (1986) made an experiment and successfully applied in practice the idea for the matrix presentation of the arithmetic operations addition and subtraction during the education in mathematics.

For example: $15+3=18 \longrightarrow 18-3=15$

$$
3+15=18 \longrightarrow 18-15=3
$$

According to Erdniev and Angelova (Angelova, 2013, pp.19-20) "the matrix presentation of knowledge would allow the observant student to see several interconnected elements of the mathematical knowledge that form certain structural unity.

Applying the matrix approach will help the students understand the relation between the connected arithmetic operations, facilitate the reproduction of information, and the transition from one action to another. If students have understood the structure of the matrix and the logic of composing its elements, then they can find all these elements after knowing only some of them".

If during the education in mathematics teachers use tasks related to the inverse relations between the arithmetic operations addition and subtraction, will this help the students for more in-depth and successful mastering of these arithmetic operations?

\section{Methodology}

A new methodology system of work for teaching inverse operations addition and subtraction with numbers up to 20 was developed for grade 1 . The system was tested during the period $2016-2020$ in the following primary schools in the town of Stara Zagora, Bulgaria: Dimitar Blagoev elementary school, Petko Rachov Slaveykov second elementary school, St. Nikola Primary school, and Vassil Levsky elementary school. The system included tasks that help the first-graders to acquire knowledge and skills regarding the above-mentioned inverse arithmetic operations. Some of these tasks are presented below. 
According to this methodology of work, the learning of the algorithms of the arithmetic operations addition and subtraction can be done simultaneously, in parallel, and in sequentially. The concrete approach depends on the specifics of the educational content and the grade 1 students' abilities to perceive and process information.

In parallel with the introduction of the numbers up to 10 , students get familiar with addition and subtraction operations with the particular number they have learned. These operations shall be introduced simultaneously in one lesson based on the set-theoretical approach in an implicit form (without using terminology and symbols), combined with counting.

Considering the abstraction stages of introducing these two arithmetic operations, initially, the students initially manipulate and perform practical activities with sets of concrete objects. Then follows work with an illustration of objects, substitutes for specific objects and their illustrations (little sticks, abacus balls, etc.), and finally mathematization of the operations with the object sets using numbers and signs.

The students are required to put on the desk 4 cubes and to add 1 more. After a discussion between the teacher and the students, it is found out that the total number of cubes is 5. After that, the students are required to take out 1 cube from the set of 5 cubes and to find out how many cubes remained. The answer is 4 . The teacher may also allow the students to work on their desks with an abacus or with small sticks. To realize the meaning of the arithmetic operations addition and subtraction of numbers up to 10 the students look at depicted practical situations, compose and calculate respective numerical expressions.

Below is presented one of the tasks included in the new methodology system of work which is used for the introduction of the algorithms for addition and subtraction of the numbers up to 8 (Bogdanova, Temnikova, 2016, p.33):

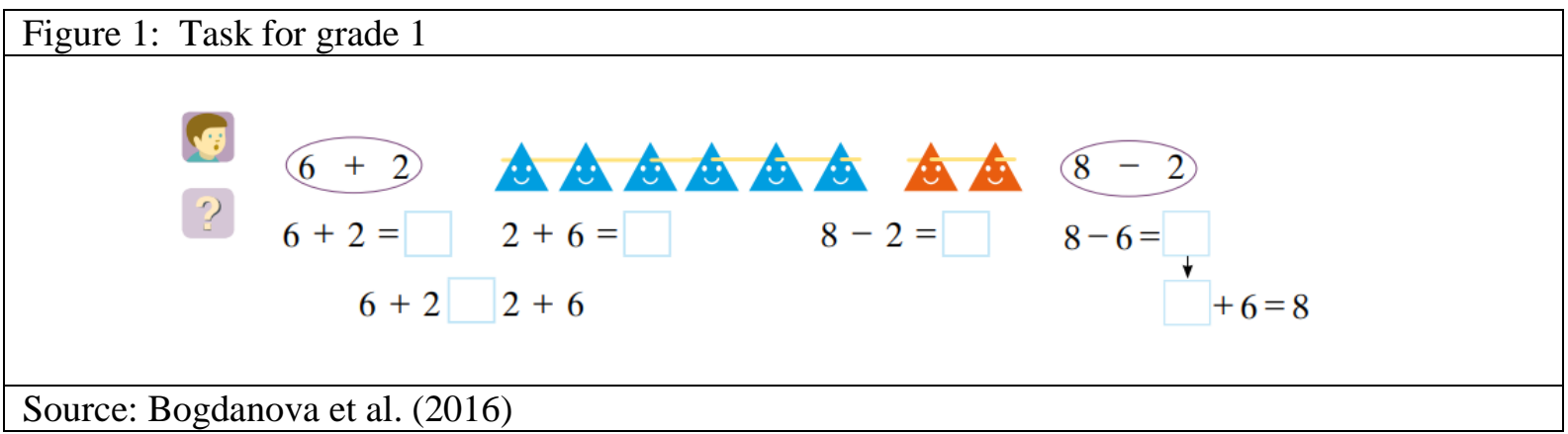

To understand the relation between the operations addition and subtraction, students work on depicted situations and solve two text tasks one after the other with one calculation: the first one for addition and the second one for subtraction. For example:

Task: Danny has got 6 toy cars. He has been given another 3. How many toy cars in total have got Danny?

Students calculate using the numerical expression $6+3=9$ that the total number of toy cars which Danny has got is 9 .

Task: Danny has got 9 toy cars. He gave 3 of them to his brother as a present. How many toy cars remained to Danny?

Students calculate the numerical expression $9-3=6$ (6 toy cars remained to Danny).

One of the options for works is for the students to compose these text tasks.

The below tasks are included in the methodology work in a system:

$7+2=9 ; 9-7=2 ; 9-2=7$

For each task for addition from the type $6+2=8$ the first-graders should get used to compose two numerical expressions for subtraction from the type $8-6=2$ and $8-2=6$. They must learn to calculate differences by the given sum of two numbers. This will develop students' thinking and will facilitate their ability to calculate.

In the new methodology system of work, the following tasks (Bogdanova, Temnikova, 2016, p.81) were proposed: 


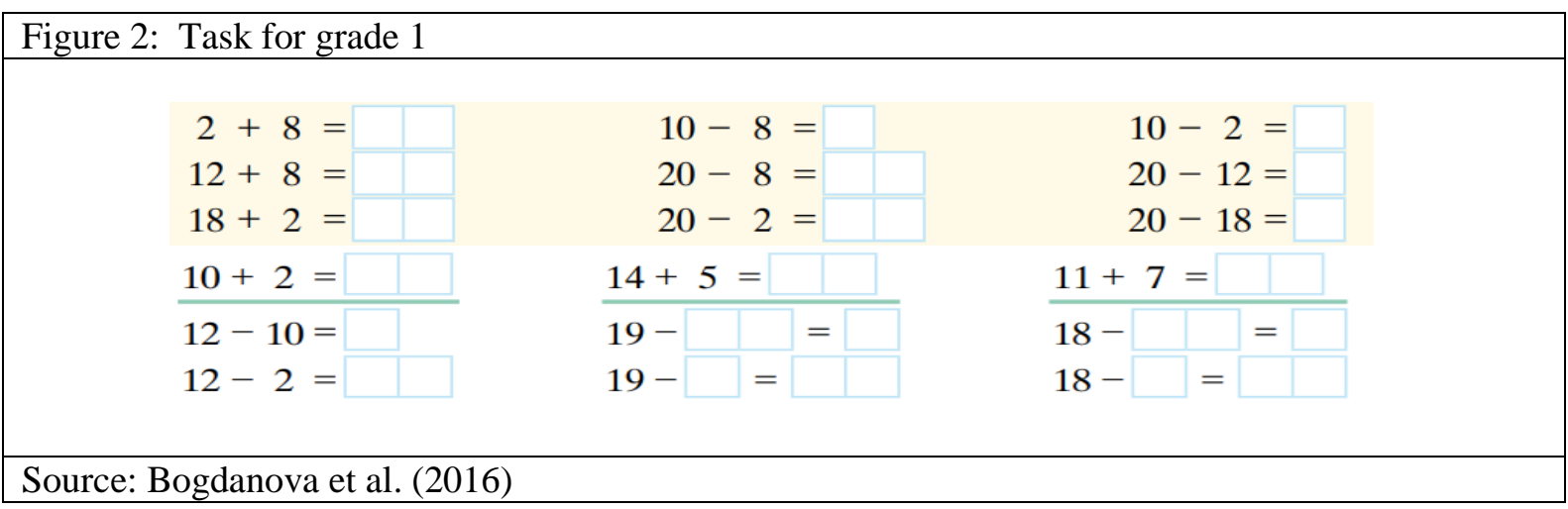

Some of the tasks (Bogdanova, Temnikova, 2016, p. 68) included in the methodology system are given in the tabular form. These types of tasks use the name of the components for the arithmetic operations addition and subtraction: addend, sum, minuend, diminutive, and difference.

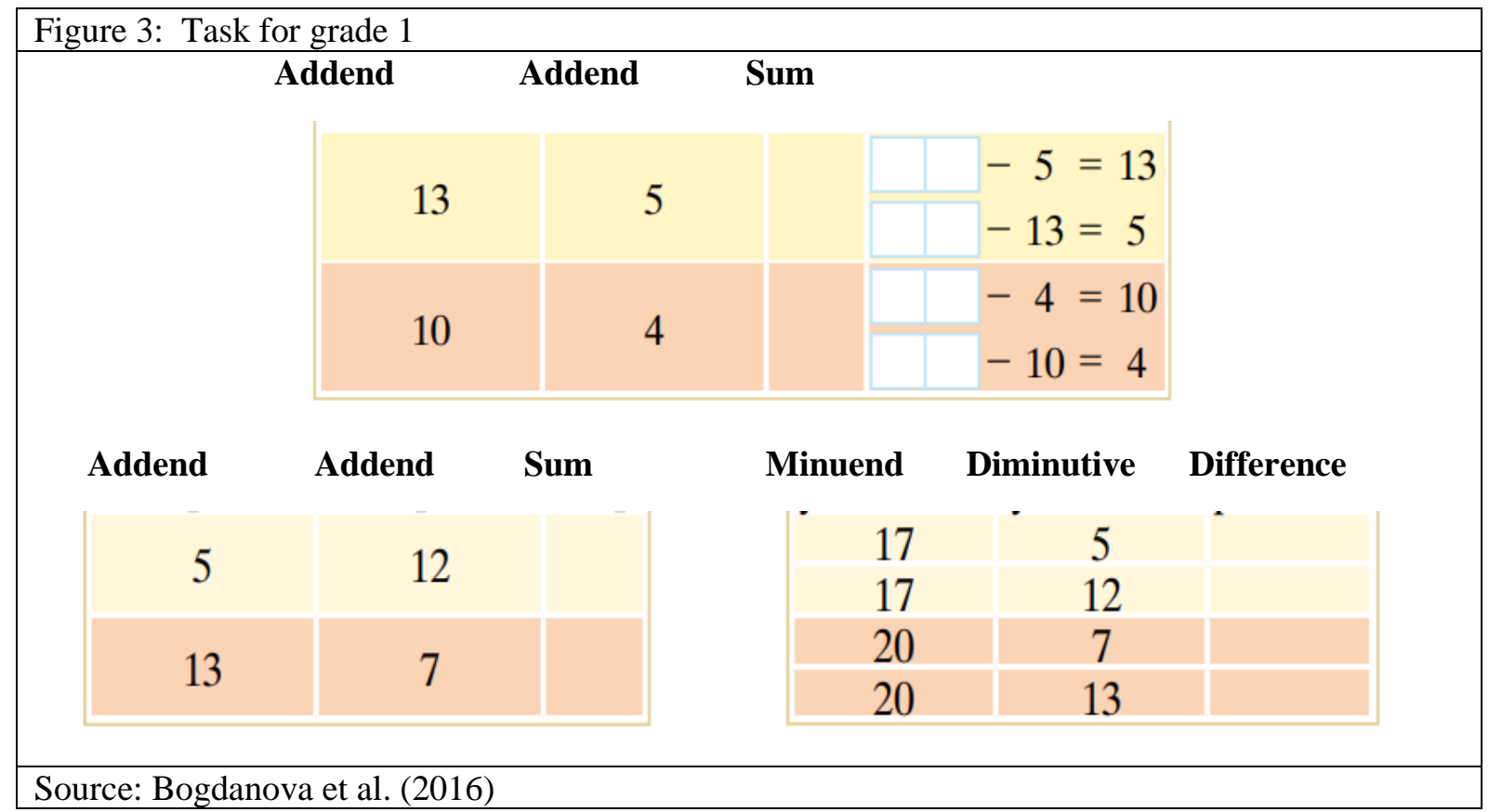

It will be appropriate to include tasks like the ones given below:

Task: If you know that $13+5=18$ then find without calculating how much is $18-13$.

Task: If you know that $17-9=8$, then find without calculating how much is $8+9$.

After studying the numbers $11,12, \ldots, 19,20$ according to the educational program in mathematics for grade 1 the teacher shall introduce the arithmetic operations addition and subtraction without passing the ten simultaneously during one single lesson. The cases related to subtraction can be explained based on the operation addition.

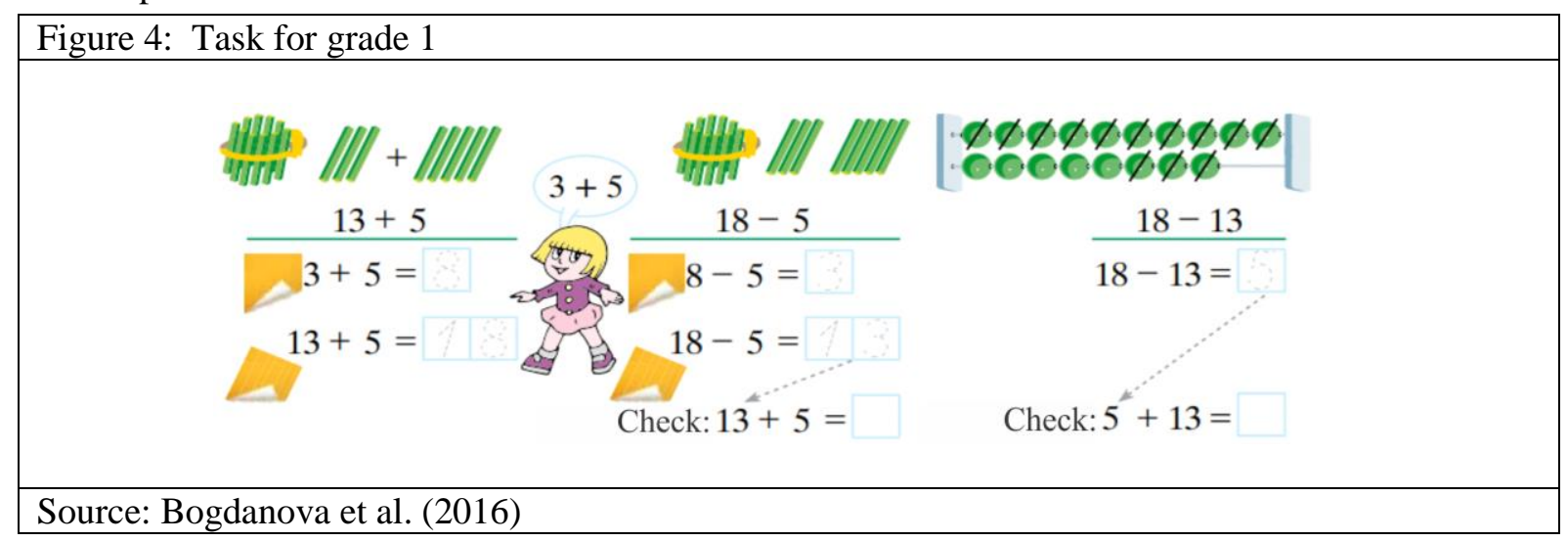


After clarifying that $14+3=17$, students are required to calculate the difference $17-3=$ ? using the relation between the arithmetic operations addition and subtraction, i.e. from $14+3=17$ follows that $17-3=14$.

Novakova (Novakova, 2004, p.131) noted that "in fact, students must receive from one true reasoning another true reasoning, i.e., reasoning which follows an initial one. This develops the thinking".

The methodology system of work includes tasks (Bogdanova, Temnikova, 2016, p. 57) like the one in Figure 4.

One important skill which students must develop is to learn how to check the results from the operation subtraction using the operation addition. This is one of the applications of the relation between the two operations. For example: $11-5=13$, Check: $13+5=18$. Through the operation addition, students check if the operation subtraction has been correctly done. For learning each new algorithm for subtracting the numbers up to 20 the methodology system checks the results from operation subtraction with operation addition. For learning algorithms for addition and subtraction of numbers up to 20 with passing the ten, an inverse relation between the arithmetic operations addition and subtraction are used for better results. The methodology system offered the following task (Bogdanova, Temnikova, 2016, p. 96):

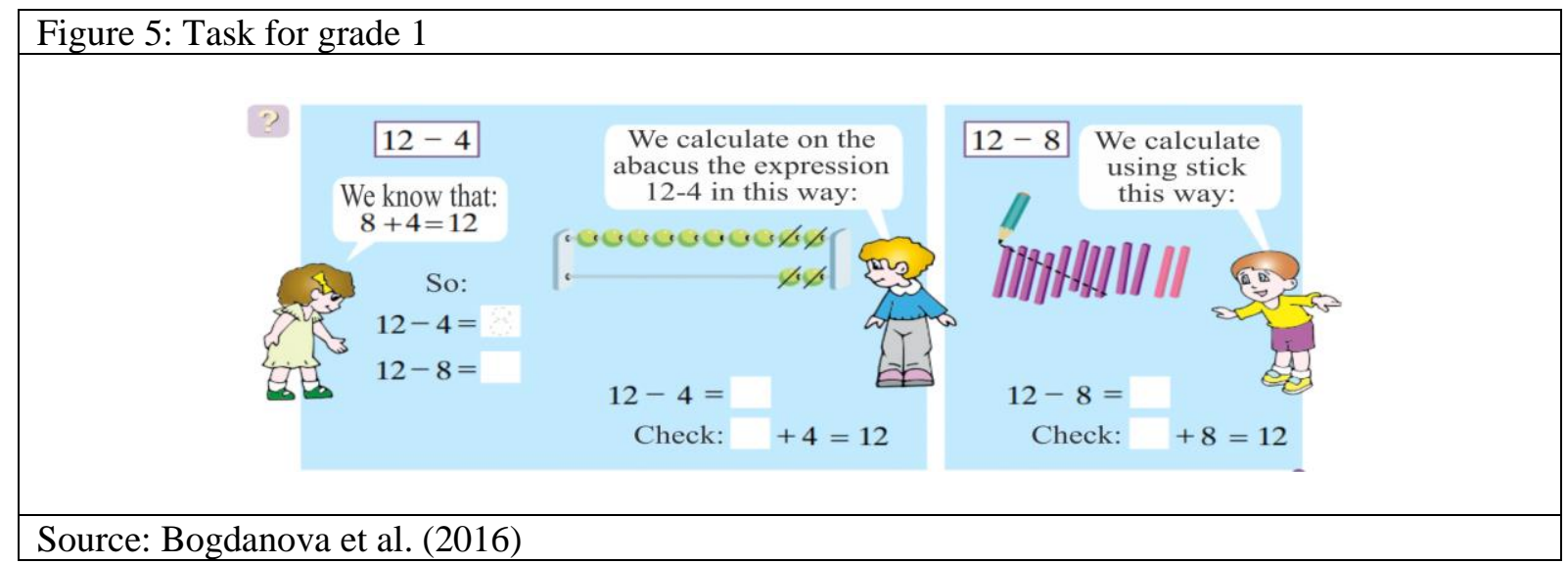

When a student faces difficulties finding the sum or the difference between given numbers, he/she must be given the freedom to do the calculation in different ways: in addition to different means of visualization, the relation between addition and subtraction can be used.

To find an unknown component in an equation with the known result and known other components students can also use the relations between the arithmetic operations addition and subtraction. In the next grades of the Primary school on this basis, teachers introduce the rules for finding an unknown addend, an unknown minuend, and an unknown diminutive. The below task (Bogdanova, Temnikova, 2016, p. 22) is one of the tasks included in the methodology system of work:

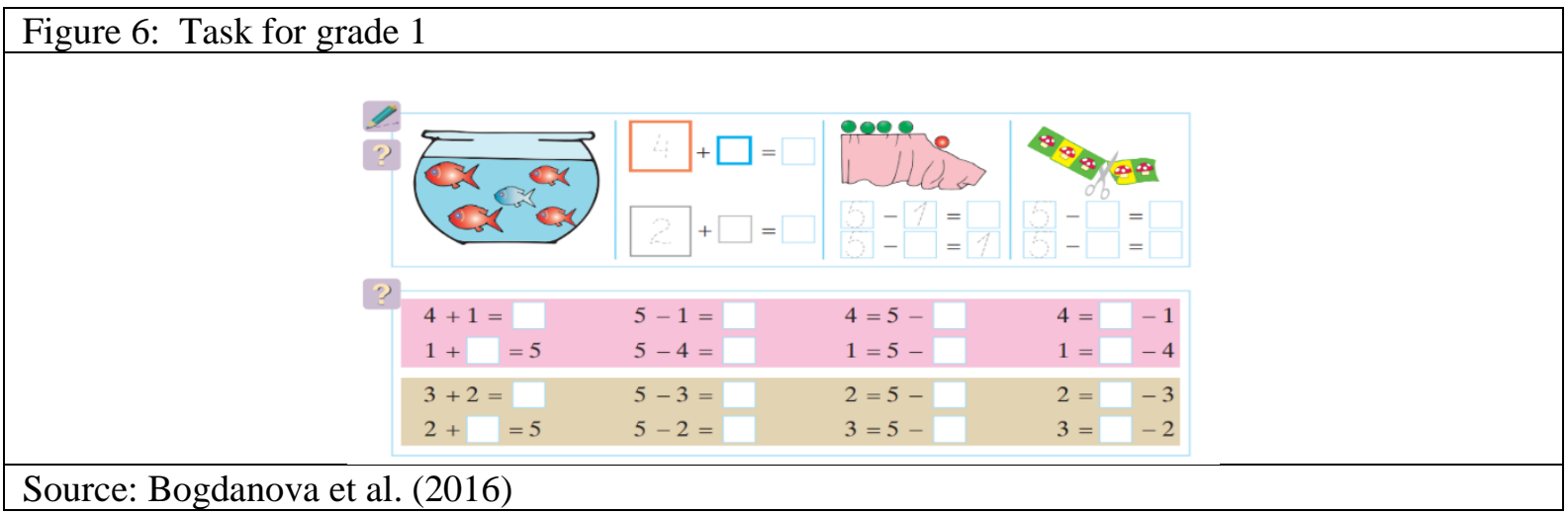

Grade 1 students experience certain difficulties with tasks that include inverse relation between the arithmetic operations addition and subtraction and where they have to fill in an omitted sign for an arithmetic operation. One such task (Bogdanova, Temnikova, 2016, p. 103) is given below: 


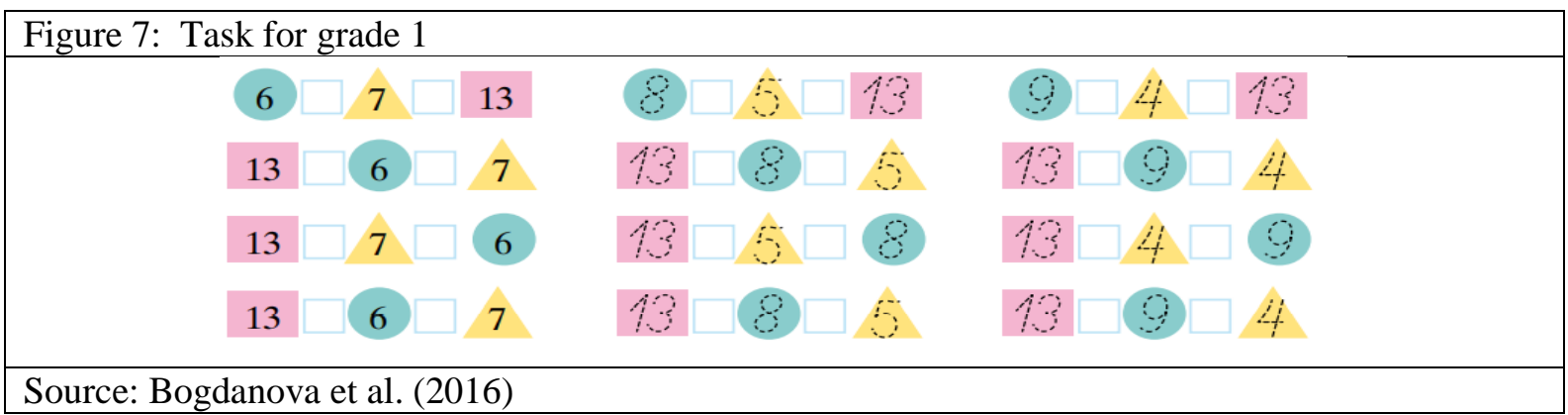

\section{Results}

During the period 2016-2020, the methodology system of work was applied in the elementary schools mentioned in the Methodology section of this work. In 2020 two grade 1 class with statistically equal levels of educational achievements were studied. One of the classes was the experimental one, where the new methodology system of work was applied. The second class was the referent one where this system was not applied.

Two tests have been used in empiric research. The first test was to determine the entry diagnostic and the second one to determine the exit diagnostic of the students' knowledge and skills to solve arithmetic tasks related to the operations of addition and subtraction. The researcher studied the objectiveness, validity, and reliability of the tests as well as the level of difficulty and the separating force of the tasks included in the tests.

The entry diagnostic results showed no statistically significant difference between the relative shares of the students from the experimental and the referent class subjected to the research work in respect of the studied knowledge and skills. After completing the experimental work, the exit diagnostic identified a significant difference between the results of the students from the experimental class compared with the results of the students from the referent class.

The level of knowledge and skills of the experimental class's first-graders who correctly solved the task related to checking the operation subtraction with operation addition increased from $42.9 \%$ to $91.5 \%$. The percentage of the students who made mistakes in solving one of the most difficult tasks for the firstgraders related to subtraction of numbers up to 20 with passing the ten. This percentage for the students from the experimental class was $6.3 \%$, and for the students from the referent, the class was $36.1 \%$. $94.3 \%$ of the students from the experimental class correctly solved the tasks where they were required to compose two numerical expressions for subtraction by a given numerical expression. This task was successfully solved by $64.7 \%$ of the students from the referent class. The difference between the results was proved to be statistically significant.

I have found that solving tasks related to the connections between the arithmetic operations addition and subtraction had increased the first grade students' level of knowledge and skills regarding the operations addition and subtraction of numbers up to 20 .

\begin{tabular}{|l|l|l|l|l|l|}
\hline Figure 8: Exit diagnostic for knowledge and skills of the students \\
\hline Source: Author
\end{tabular}




\section{Conclusions}

After applying the new methodology system of work, the students from the experimental class achieved higher results in solving tasks related to the arithmetic operations addition and subtraction. Studying the connection between addition and subtraction helped the students to understand the nature of these arithmetic operations better. Students successfully used the connection for solving different arithmetic tasks and to do arithmetic operations consciously. This facilitated the grade 1 students to acquire knowledge, skills, and competencies from competency Cluster Numbers and those related to mental addition and subtraction as well as to develop their thinking. The formalism in their knowledge is overcome, and a creative approach is realized for assimilation of these operations.

Therefore, in his methodology work, the teacher must use tasks related to the inverse relation between the arithmetic operations addition and subtraction. This will help the grade 1 students increase the level of their knowledge about these arithmetic operations.

\section{References}

Angelova, Vl. (2013), Metodika na izuchavane na vzaimovrazkite mezhdu aritmetichnite deystvia v nachalnoto obuchenie po matematika [Methods of studying the relations between arithmetic operations in primary education in mathematics]. Management and education, vol. IX (3), 18-20.

Bogdanova,M., M. Temnikova, (2016). Matematika za parvi klas [Mathematics for grade 1]. Sofia, Bulgaria: Klet, Bulvest 2000 Publisher, 22, 33, 57, 68, 81, 96, 103.

Bogdanova,M., M. Temnikova, (2016). Tetradka № 2 po matematika za parvi klas [Notebook No.2 in mathematics for Grade 1]. Sofia, Bulgaria: Klet, Bulvest 2000 Publisher, 22.

Campbell, J. I. D. (2008). Subtraction by addition. Memory \& Cognition, 36 (6), 1094.

Erniedev, P. M., B. P. Erniedev, (1986). Ukrupnenie didakticheskih edinits v obuchenie matematike [Consolidation of the didactical units in education in mathematics]. M., Prosveshtenie editor.

Kllogjeri, P., L. Kllogjeri, (2015). Dynamic Models for Addition and Subtraction. Open Access Library Journal, 2 : e1814. http://dx.doi.org/10.4236/oalib.1101814.

Mastrothanasis, K., A. Geladari, K. Zervoudakis, P. Strakalis, (2018). Primary school pupils' strategies for mental addition and subtraction computations. International Journal of Education and Research, Vol. 6 No. 8.

Mukunthan, Th. (2021). Primary school children's errors in addition, Asian Journal of Multidimensional Research, Vol 10, Issue 3.

Munasinghe, D.M.W. (2013). A study on error patterns in "Addition" in primary school children (7 years old children). Merit Research Journal of Education and Review 1 (7).

Novakova, Z. (2004). Metodika na obuchenieto po matematika v nachalnite klasove [Methodology of education in mathematics in Primary school]. Hermes editor, 131.

Nunes, T., P. Bryant, D. Hallett, D. Bell, D. Evans, (2009). Teaching children about the inverse relation between addition and subtraction. Mathematical Thinking \& Learning, 11(1/2).

Parwines, Z., A. Noornia, (2019). Is it required to remove borrowing techniques in clearly subtraction operations in elementary school? Journal of Physics: Conference Series 1157042076.

Stigler, J. W., K. C. Fuson, M. Ham, M. S. Kim, (1986). An Analysis of Addition and Subtraction Word Problems in American and Soviet Elementary Mathematics Textbooks. Cognition and Instruction.

Thirunavukkarasu M., S. Senthilnathan, (2014). Effectiveness of bar model in enhancing the learning of mathematics at primary level. International Journal of Teacher Educational Research (IJTER), Vol.3 No.1.

Torbeyns, J., Gr. Peters, B. De Smedt, P. Ghesquièreb, L. Verschaffel, (2018). Subtraction by Addition Strategy Use in Children of Varying Mathematical Achievement Level: A Choice/No-Choice Study. Journal of Numerical Cognition, Vol. 4(1). 